\title{
Editorial: efficient design in a modern engineering world - the challenges
}

Benedict D. Rogers MEng (Hons), DPhil (Oxon), FHEA

Senior Lecturer, Modelling and Simulation Centre (MaSC), School of Mechanical, Aerospace and Civil Engineering, University of Manchester, Manchester, UK

The Engineering and Computational Mechanics (EACM) journal always publishes articles that highlight searching questions in engineering that demand greater attention and awareness. This issue of EACM publishes three papers that highlight an important issue now facing the engineering industry, namely how do we ensure efficient design in a modern engineering world.

Wright et al. (2017) present a review of air-water interactions in urban drainage systems focusing on partially filled drainage conduits. In particular they emphasise the role of air intrusions in vertical conduits. They bring specific attention to the twocomponent pressure approach (TPA) which 'appears to be quite robust in modelling single-phase (water) flow in rapidly filling systems' (Wright et al., 2017: p. 105) without the need to launch more computationally expensive two-phase simulations such as computational fluid dynamics (CFD) models. Usefully, they also highlight the new directions of research that are needed in this area.

Continuing the theme of efficient design, Herfelt et al. (2017) present a new approach for numerical limit analysis of concrete structures by proposing a new lower bound plane stress element. Demonstrating the rigour of the approach with convergence studies and error analysis, their method enables the evolution of current engineering practice from manual upper and lower bound limit state analysis, which is subject to the skill of the structural engineer, to a more robust numerical limit state analysis. This enables the modelling of complex structures with a satisfactory accuracy. As the authors state, 'even large problems can be solved in a matter of minutes on a standard laptop' (Herfelt et al., 2017: p. 116).

Finally, Ivanović et al. (2017) offer a new design for ground anchor heads to optimise the quality of load estimation for non-destructive ground anchorage integrity testing. Even now, as the authors argue, 'present practices of assessing anchorage quality and performance are limited, time consuming or destructive' (Ivanović et al., 2017: p. 118). Non-destructive testing is not a new concept, but it is one that needs continual revisiting to improve the quality of our ability to understand and design elements such as ground anchors. Using both experimental and numerical finite-element studies, they demonstrate that their new plate design is both viable and suitable for engineering practice and will inform better design for the future.

All three of these papers highlight an ever-present problem that has the potential to grow in severity in the foreseeable future. With many state-of-the-art engineering tools, the expertise required to use and understand them is beyond the vast majority of engineers in the modern workplace, where solutions are expected quicker, more efficiently and more accurately than ever. This complexity is moving in the opposite direction to the current trend with the ease-of-use 'apps' now widely available on so-called smart devices.

With all the funding being invested into academic and industrial research highlighting the ever greater complexity of either the underlying governing processes or the effects of engineering practices (be they physical, behavioural, numerical or analytical), how does the modern civil, mechanical, aerospace or chemical engineer make sense in a pragmatic way of a world of engineering theories and tools of ever-increasing complexity?

Engineers have always been the members of society to provide timely pragmatic solutions to problems facing communities. The challenges we must address as an engineering collegiate community include, but are not limited to, the following

- developing efficient design tools and procedures that do not sacrifice the wealth of understanding and sophisticated engineering analyses increasingly at our disposal

- defining satisfactory accuracy for complex systems for engineering use

- future-proofing our engineers to facilitate maintaining their understanding of such sophisticated new developments 
- identifying potential pitfalls in engineering practice, particularly when this involves the use of software packages commonly used throughout the industry (Rogers, 2015; Wright et al., 2017).

These are challenges for the entire engineering industry. The papers in this issue of EACM offer a possible preview into how such a future might evolve. They also highlight that this process will not be quick or straightforward.

\section{REFERENCES}

Herfelt MA, Poulsen PN, Hoang LC and Jensen JF (2017) Lower bound plane stress element for modelling 3D structures. Proceedings of the Institution of Civil Engineers - Engineering and Computational Mechanics 170(3): 107-117, http://dx.doi.org/10.1680/ jencm.16.00026.

Ivanović A, Monese A and Neilson RD (2017) Optimisation of ground anchor head for non-destructive testing. Proceedings of the Institution of Civil Engineers - Engineering and Computational Mechanics 170(3): 118-131, http://dx.doi.org/10.1680/ jencm.16.00012.

Rogers BD (2015) Editorial. Proceedings of the Institution of Civil

Engineers - Engineering and Computational Mechanics 168(1): 1-2, http://dx.doi.org/10.1680/eacm.2015.168.1.1.

Wright SJ, Vasconcelos JG and Lewis JW (2017) Air-water interactions in urban drainage systems. Proceedings of the Institution of Civil Engineers - Engineering and Computational Mechanics 170(3): 91-106, http://dx.doi.org/10.1680/jencm.16.00024. 